\title{
The Relationships between Functional and Dysfunctional Impulsivity and Aggression across Different Samples
}

\author{
Andreu Vigil-Colet, Fabia Morales-Vives, and Jordi Tous \\ Universitat Rovira I Virgili (Spain)
}

\begin{abstract}
E. S. Barratt proposed the term impulsive aggression to define a kind of aggression that is characterized by acting without thinking because of high levels of impulsivity. Previous research using psychometric measures has shown that impulsivity and aggression are related as far as psychometric measures are concerned. Nevertheless, most of the research has been done with samples of university students. Our research tests whether this relationship is stable across different samples; university students, teenagers and workers. Our results show that impulsivity and aggression have a consistent pattern of relationships across these samples, with impulsivity being specially related to emotional and instrumental aspects of aggression. Furthermore, the effects of anger on aggression seem to show a pattern of relationship that depends on age, with a tendency to physical aggression in young people and verbal aggression in adults.
\end{abstract}

Keywords: impulsivity, impulsive aggression, anger

E. S. Barratt ha propuesto el término agresión impulsiva para definir un tipo de agresión que se caracteriza por actuar sin pensar debido a altos niveles de impulsividad. Investigaciones anteriores con medidas psicométricas han mostrado que impulsividad y agresión están relacionadas en lo que a las medidas psicométricas se refiere. Sin embargo, la mayoría de las investigaciones han empleado muestras de estudiantes universitarios. Nuestro trabajo trata de comprobar si esta relación se mantiene en muestras diferentes. Nuestros resultados indican que impulsividad y agresión muestran una pauta de relación consistente across these samples, estando la impulsividad especialmente relacionada con los aspectos emocionales e instrumentales de la agresión. Además, los efectos de la ira sobre la agresión muestran al parecer una pauta de relación dependiente de la edad, encontrándose una tendencia a la agresión física en gente joven y la agresión verbal en adultos.

Palabras clave: impulsividad, agresión impulsiva, ira

This research was partially supported by a grant from the Catalan Department of Universities, Research and the Information Society (2005SGR00017), and by a grant from the Spanish Ministry of Education and Science (SEJ2005-09170-C04- 04/PSIC), with the collaboration of the European Fund for the Development of Regions.

Correspondence concerning this article should be adressed to Andreu Vigil-Colet, CRAMC (Research center for behaviour assessment), Departament de Psicologia, Facultat de C.C. E. E. i Psicologia, Universitat Rovira i Virgili, 43007 -Tarragona, Spain. E-mail: avc@urv.cat.

How to cite the authors of this article: Vigil-Colet, A., Morales-Vives, F. and Tous, J. 
There is a general consensus on the multidimensional nature of impulsivity but there is also a lack of agreement about the number of dimensions that this construct contains. Several authors have tried to determine the number and nature of these dimensions by applying factor analysis or structural equation modelling to various self-report measures of impulsivity (Gerbing, Ahadi, \& Patton, 1987; Miller, Flory, Lynam, \& Leukefeld, 2003; Miller, Joseph, \& Tudway, 2004; Whiteside \& Lynam, 2001). Although these analyses proposed a different number of dimensions, most of them agree that certain scales tend to show high loadings on the same factor. In this respect, Whiteside and Lynam (2001) and Miller et al. (2004) found that the Dysfunctional Impulsivity (DI) scale of Dickman's Impulsivity Questionnaire (Dickman, 1990), the Impulsivity scale of Eysencks' I7 (NI) Impulsivity Questionnaire (Eysenck, Pearson, Easting, \& Allsopp, 1985) and the three Impulsivity scales of Barrat's Impulsiveness Scale-11 (BIS-11; Patton, Stanford, \& Barratt, 1995) loaded on the same dimension. Furthermore, Vigil-Colet (2007) recently showed that the disattenuated correlation coefficient between DI and the NI is around 1, so both scales seem to measure the same dimension. On the other hand, the same studies show that functional impulsivity (FI) and venturesomeness (VE) scales tend to load on a different factor.

The concepts of functional and dysfunctional impulsivity were proposed by Dickman (1990). He suggested that impulsivity involved at least two distinct and independent forms. The first is functional impulsivity, which is related to a tendency to take quick decisions when this is appropriate to the situation. The second is dysfunctional impulsivity and is related to speedy and non-reflexive decisions, which have negative consequences for the individual. This distinction is similar to Eysenck's (1997) distinction between extraverted impulsivity and psychotic impulsivity: the former is the process of taking decisions with a calculated risk, while the latter is the process of taking decisions that do not take into account the associated risks and consequences of the action.

Several studies have shown that impulsivity is related to deficits in inhibitory control. People scoring high on impulsivity questionnaires showed lower cognitive inhibition than low impulsives, and had greater difficulty at inhibiting prepotent responses (Avila \& Parcet, 1997; Horna, Dolan, Elliott, Deakin, \& Woodruff, 2003; Logan, Schachar, \& Tannock, 1997). Nevertheless, the difficulty that impulsive individuals have in inhibiting responses seems to be more related to some scales of impulsivity than to others. In this respect, Logan et al. (1997) found that individuals with high scores on the impulsivity items of the Eysenck Personality Inventory had longer reaction times to a stop signal; Marsh, Dougherty, Mathias, Moeller, and Hicks, (2002) found that individuals with high scores in NI showed poorer responses to an inhibition signal than individuals with lower scores. Finally, Vigil-Colet and Codorniu-Raga (2004) found that DI and NI are related to inhibition deficits in a Stop-Go task while FI and VE are not related to performance on this task. In the psychophysiological domain,
Horna et al. (2003) found that differences in the cortical areas activated during Stop-Go tasks were a function of the scores of the individuals on the NI scale and the total score of BIS11 , and that more impulsive individuals activated paralimbic areas while less impulsive individuals activated higher association areas when they had to inhibit a response. These results suggest that inhibition deficits are more related to such dimensions as dysfunctional and narrow impulsivity than others such as functional impulsivity.

The difficulty to inhibit certain responses seems to be one of the most important elements in certain kinds of aggression and, especially in impulsive aggression. Impulsive aggression refers to unplanned and spontaneous aggressive acts which are unprovoked or out of proportion to the provocation, and is related to the personality trait of impulsivity, characteristic of those who usually respond aggressively without thinking and who often show guilt afterwards (Barratt, Stanford, Dowdy, Liebman \& Kent, 1999). Barratt (1991) defined them as individuals who have a tendency to "lose their temper easily" and are unable to control certain behaviours.

In order to explain this kind of aggression, Barratt (1994) proposed that some people are predisposed to responding to certain stimuli or situations with feelings of anger, which may lead to an aggressive response. If such a predisposition is combined with a high level of impulsivity, then the difficulty of inhibiting responses facilitates aggressive behaviour. Nevertheless, results from cognitive and psychophysiological domains modified Barratt's hypothesis and it was proposed that impulsiveness and anger are necessary but not sufficient in themselves for impulsive aggression.

Results seem to indicate that impulsivity is an obstacle to learning in the early developmental years, leading to poor problem solving which is the direct cause of aggression. In fact, impulsivity is negatively related to measures of crystallized intelligence and scholastic failure, and not related to measures of fluid intelligence, which may indicate the existence of learning difficulties associated with impulsivity (Fink \& McCown, 1993; Vigil-Colet \& Morales-Vives, 2005)

Although Barratt's model proposes an explanation for the links between impulsivity and aggression, relatively few studies have attempted to relate psychometric measures of impulsivity and aggression, and their results are contradictory. In this respect, McMurran, Blair, and Egan (2002) failed to find any relationship between BIS-11 and the scales of the Aggression Questionnaire (Buss \& Perry, 1992). Other authors, however, have found that the scores of impulsive aggressors on the BIS-11 total scale are higher than those of a control group, and that both the total score of the BIS-11 and the Motor and Cognitive Impulsivity scales are related to the four scales of the Aggression Questionnaire. The results for the non-planning scale, on the other hand, are contradictory (Archer \& Webb, 2006; Helfritz \& Stanford, 2006; Marsh, Dougherty, Mathias, Moeller, \& Hicks, 2002; O'Connor, Archer, Hair, \& Wu, 2002; Ramirez \& Andreu, 2006). On the other hand, Archer, Kilkpatrick, and Bramwell (1995) 
found that the impulsivity scale of the Gladue Aggression Inventory correlated positively with all the scales of the AQ. The scale that was most related to impulsivity was anger.

Finally, Vigil-Colet and Codorniu-Raga (2004) used Dickman's Impulsivity Inventory (DII) (Dickman, 1990) and Eysenck's Impulsivity Inventory to find that Venturesomeness and Functional Impulsivity (FI) were not related to most of the AQ scales but that Dysfunctional Impulsivity (DI) and Narrow Impulsivity were related to the Physical, Verbal and Anger scales of the AQ and with inhibitory deficits in an experimental task but not with the Hostility scale. These results seem to show that narrow and dysfunctional impulsivity are related to the instrumental and emotional components of aggression but not to the cognitive aspects measured by the Hostility scale. Moreover, these relationships seem to be due to deficits at the inhibitory level, which is consistent with Barratt's proposals about impulsive aggression.

The results presented above indicate that although impulsivity and aggression are related at a psychometric level, it is not clear which components of impulsivity are related to aggression or which AQ subscales are related to impulsivity. Most of these studies also have another common problem: the sample used. Most of them analyse the relationships between impulsivity and aggression in adult samples consisting of university students. The findings, then, may be influenced by the specific characteristics of this population and by possible rank restriction effects.

The present study analyses the relationships between impulsivity and aggression measured by DII and AQ across different samples and ages. We believe this to be an important issue because the relationships between variables found in one research project are often generalized to populations that are not included in the research. This is one of the most common threats to external validity (Shadish, Cook, \& Campbell, 2002) To this end, we administered both measures not only to a sample of university students, but also to two different samples of factory workers and adolescents. The main purpose of the study is to determine whether the relationships between impulsivity and aggression - if they are found-are stable across different populations and whether these relationships are coherent with Barrat's theory about impulsive aggression. We expect aggressive behaviours to be more related to dimensions of impulsivity connected to inhibition deficits such as DI than to other dimensions such as FI. This is the main reason for using DII instead of other instruments designed to measure impulsivity, such as Barratt's BIS-11, which in previous research have shown a similar pattern of relationships between all or most of their scales and aggression (Marsh et al., 2002; Morales-Vives, 2007; O’Connor et al, 2002).

We also aim to determine whether aggression is sensitive to sex differences. Taking into account that many studies have found consistent differences in aggression between men and women, particularly in physical aggression (Archer, 2004), we are specifically interested in analysing whether these differences in physical aggression are stable across different samples.
Method

\section{Participants}

The participants were 780 individuals (360 males and 420 females) aged between 12 and 60 years with a mean of 24.90 years $(S D=10.42)$ belonging to three different Catalan samples:

1. Sample 1. The participants were 216 volunteer undergraduate students of psychology at the Rovira i Virgili University (44 males and 172 females). As is usual in psychology student samples there was a high proportion of females. The age range of this sample was 18 to 48 years, with a mean of 22.97 years $(S D=5.5)$.

2. Sample 2. The participants were 241 volunteer secondary school students (107 boys and 134 girls) from two state schools in Tarragona. The participants were between 12 and 17 years old $(M=14.20, S D=$ 0.98).

3. Sample 3. The participants were 323 individuals (209 males and 114 females) working in the car spare parts trade. The participants were between 21 and 60 years old $(M=34.20, S D=8.18)$. These measures were obtained during a psychosocial risks assessment study.

\section{Procedure}

All tests were administered in groups of between 15-20 individuals by professional psychologists.

\section{Measures}

Dickman's Impulsivity Inventory (DII). We used the Spanish adaptation of Dickman's inventory. An analysis using consensus oblimin rotation showed that the factorial structure of this adaptation is equivalent to both the original version and adaptations in other languages. Its internal consistencies are of 0.78 and 0.76 for functional and dysfunctional impulsivity, respectively (Chico, Tous, Lorenzo-Seva \&Vigil-Colet 2003).

The Buss and Perry Aggression Questionnaire (AQ). The Spanish adaptation of the AQ was used (Andreu, Peña, \& Graña, 2002). The questionnaire measures physical aggression (PA), verbal aggression (VA), anger (AN) and hostility (HO) corresponding to the behavioral, emotional and cognitive aspects of aggression, respectively. This adaptation shows a good fit to the four factor model proposed by Buss \& Perry (1992) and it is free of sex bias, showing internal consistencies of $0.82,0.77,0.68$ and 0,75 for PA, VA, AN and HO respectively (Condon, MoralesVives, Ferrando, \& Vigil-Colet; 2006; Morales-Vives, Codorniu-Raga, \& Vigil-Colet, 2005). 


\section{Results}

Table 1 shows descriptive statistics for all psychometric measures across samples and genders. We performed a factorial MANOVA to test sample and gender effects on psychometric measures. In order to assure that sample differences were not merely showing age differences, we introduced age as a covariate in the analysis. It proved to be non significant $\left(F_{6,746}=1.89, p>0.05\right)$ so we performed the analysis without it. Both main effects were significant while no significant effect was found for the interaction. The sample factor had a significant effect on the psychometric measures (Pillai's $=0.335 \mathrm{p}<0.01$; $\eta^{2}=0.167$ ). Post-hoc univariate ANOVAs showed that the sample had significant effects on all measures at the $\alpha=0.01$ level with the exception of FI which was significant at $\alpha=$ 0.05 . Moreover, the sample had a considerable effect on PA $\left(\eta^{2}=0.22\right)$ and moderate or slight effects on the other measures. Taking into account these results, we performed pair-wise comparisons using Tukey's test to determine which samples were responsible for these effects. Tukey's test showed that at the $\alpha=0.01$ level the effects on DI, PA, AN, $\mathrm{HO}$ and the full scale of the AQ were due to the higher scores of the adolescents group, while for the FI scale and the VA scale of the AQ the effects were due to the higher and lower scores of workers, respectively. Nevertheless, the effect sizes for FI and VA were quite slight (less than 2\%). We also compared adolescents and adults by grouping the university and worker samples. This comparison showed that adolescents scored significantly higher $(p<0.01)$ in DI, $\mathrm{PA}, \mathrm{AN}$ and $\mathrm{HO}$ than adults while there were no differences for FI or VA. These effects were also independent of gender. Nevertheless, because the sex ratio differed across the samples we repeated the same analysis twice, once for men and once for women, and obtained the same significant sample effects reported above, so the differences between

Table 1

Descriptive statistics for psychometric variables across samples and genders

\begin{tabular}{|c|c|c|c|c|c|c|c|}
\hline Variable & Sample & Mean & Std. De & Mean (men) & Std. Dev & Mean (women) & Std. Dev \\
\hline \multirow[t]{4}{*}{ Functional Impulsivity } & Students & 4.77 & 2.51 & 5.28 & 2.73 & 4.67 & 2.84 \\
\hline & Adolescents & 4.93 & 2.42 & 5.22 & 1.95 & 4.71 & 2.04 \\
\hline & Workers & 5.54 & 2.61 & 5.66 & 2.61 & 5.31 & 2.59 \\
\hline & All & 5.14 & 2.55 & 5.47 & 2.47 & $4.87^{(* *)}$ & 2.53 \\
\hline \multirow[t]{4}{*}{ Dysfunctional Impulsivity } & Students & 3.48 & 2.81 & 4.15 & 2.49 & 3.55 & 2.88 \\
\hline & Adolescents & 4.55 & 2.52 & 4.59 & 2.51 & 4.51 & 2.53 \\
\hline & Workers & 2.98 & 2.54 & 2.98 & 2.52 & 2.93 & 2.48 \\
\hline & All & 3.60 & 2.69 & 3.63 & 2.61 & 3.70 & 2.72 \\
\hline \multirow[t]{4}{*}{ Physical Aggression } & Students & 13.05 & 4.36 & 14.94 & 4.61 & $12.75^{(* *)}$ & 4.28 \\
\hline & Adolescents & 20.31 & 7.08 & 21.95 & 6.91 & $19.00^{(* *)}$ & 6.90 \\
\hline & Workers & 14.60 & 4.65 & 15.30 & 4.82 & $13.45^{(* *)}$ & 4.22 \\
\hline & All & 15.98 & 6.23 & 17.05 & 6.23 & $15.47^{(* *)}$ & 6 \\
\hline \multirow[t]{4}{*}{ Verbal Aggression } & Students & 12.43 & 3.37 & 12.63 & 3.42 & 12.42 & 3.30 \\
\hline & Adolescents & 12.45 & 3.88 & 12.67 & 3.92 & 12.27 & 3.93 \\
\hline & Workers & 11.48 & 3.76 & 11.84 & 3.63 & 10.81 & 3.89 \\
\hline & All & 12.04 & 3.72 & 12.24 & 3.66 & 11.90 & 3.75 \\
\hline \multirow[t]{4}{*}{ Anger } & Students & 13.45 & 4.17 & 13.58 & 3.98 & 13.82 & 4.23 \\
\hline & Adolescents & 16.00 & 4.52 & 15.68 & 4.61 & 16.26 & 4.44 \\
\hline & Workers & 14.28 & 4.10 & 14.34 & 3.82 & 14.18 & 4.58 \\
\hline & All & 14.60 & 4.37 & 14.57 & 4.13 & 14.76 & 4.52 \\
\hline \multirow[t]{4}{*}{ Hostility } & Students & 18.23 & 4.65 & 17.01 & 5.11 & 18.11 & 4.54 \\
\hline & Adolescents & 21.32 & 6.42 & 20.97 & 6.25 & 21.61 & 6.56 \\
\hline & Workers & 17.47 & 5.40 & 17.74 & 5.39 & 17.07 & 5.33 \\
\hline & All & 18.88 & 5.80 & 18.50 & 5.78 & 19.00 & 5.83 \\
\hline \multirow[t]{4}{*}{ Full Scale } & Students & 57.17 & 11.96 & 59.97 & 11.91 & 61.71 & 12.14 \\
\hline & Adolescents & 70.08 & 16.56 & 71.12 & 16.36 & 69.13 & 16.71 \\
\hline & Workers & 57.83 & 13.80 & 59.23 & 13.42 & 55.51 & 14.11 \\
\hline & All & 61.50 & 15.40 & 62.61 & 14.98 & 62.50 & 15.37 \\
\hline
\end{tabular}

${ }^{(* *)} p<0.01$ 
adolescents, university students and workers cannot be attributable to differences in sex ratios across samples.

Gender also showed significant effects (Pillai's $=0.066$ $\left.\mathrm{p}<0.01 ; \eta^{2}=0.066\right)$. Post-hoc univariate anovas showed that gender had significant effects only on PA and FI, with men having higher scores than women. Nevertheless, while the effects of gender on physical aggression were significant for all samples, the effects on FI were not significant for any of the samples.

As far as variability across samples is concerned, Levene's test showed hetereogeneity of variances for the $\mathrm{PA}, \mathrm{HO}$ and the full scale of the AQ. Posterior pair-wise $F$ tests showed that this hetereogeneity was mainly due to the higher variance of the teenager sample.

Table 2 shows product-moment correlation coefficients between impulsivity and aggression measures across the different samples. As can be seen, DI showed a significant positive relationship with all the AQ scales. This relationship is greater with PA, VA and AN than with $\mathrm{HO}$, and the correlation of DI with PA and $\mathrm{AN}(z=2.30$ and $z=2.08$ respectively, $p<0.01)$ is significantly greater than the correlation of DI with HO. Nevertheless, we have to take into account that the measures that are compared have different degrees of reliability, so the correlations are differentially attenuated. A better procedure is to compare the correlation coefficients that have been corrected for unreliability: i.e. the disattenuated correlations (e.g., Ferrando, Condon, \& Chico, 2004). In order to make a better comparison between the correlation coefficients obtained by relating DI and AQ scales, we used the internal consistencies reported by Chico et al. (2003) for DII and Morales et al. (2005) for the AQ to compute the disattenuated correlation coefficients. As Table 2 shows, when disattenuated correlation coefficients are used, the greatest relationship between DI and aggression is obtained with the anger scale, whatever sample is used.

On the other hand, FI is much less related to AQ scales than DI and most of the relationships are centered on a positive relationship with VA and a negative relationship with HO. Table 2 also shows that when partial correlation coefficients are computed controlling for DI, the relationship between FI and VA decreases but the negative relationship between FI, HO and AN even increases, which may indicate that the relationship between FI and VA is due to the association between DI and FI $(r=0.17, p<0.01)$. FI, on the other hand, is negatively related to anger and hostility levels independently of DI.

We also computed the same correlation matrix for men and women separately. Fisher's $Z$ test did not show a significant difference between the correlation coefficients for men and women relating impulsivity and aggression measures.

Table 3 shows the product-moment correlation coefficients between AQ scales across the different samples. All the relationships are positive. It is worth mentioning that anger shows the greatest relationship with physical aggression and then with verbal aggression. In general terms, it seems that high levels of anger are more associated with a physical manifestation of these feelings than with verbal aggression. Nevertheless, an examination of this relationship across the samples shows that the relationship of AN and $\mathrm{PA}$ is greater than with VA in the adolescents group $(z=$ 2.38, $p<0.01$ ) while for the university students group and the workers group AN seems more related to VA than to PA although the difference between correlations was non significant. It seems that anger in young individuals is more related to physical aggression but with age people become

Table 2

Product moment correlations between impulsivity and aggression measures across samples and partial correlations controlling for DI. The dissattenuated correlation coefficients are between brackets

\begin{tabular}{|c|c|c|c|c|c|c|}
\hline SAMPLE & SCALE & Physical Aggression & Verbal Aggression & Anger & Hostility & TOTAL \\
\hline ALL & Dysfunctional & $0.33 * *(0.41)$ & $0.25 * *(0.33)$ & $0.32 * *(0.45)$ & $0.22 * *(0.30)$ & $0.38 * *$ \\
\hline Students & Dysfunctional & $0.25 * *(0.32)$ & $0.28 * *(0.36)$ & $0.27 * *(0.38)$ & $0.06 \quad(0.08)$ & $0.29 * *$ \\
\hline Adolescents & Dysfunctional & $0.34 * *(0.43)$ & $0.22 * *(0.29)$ & $0.36 * *(0.50)$ & $0.20 * *(0.26)$ & $0.37 * *$ \\
\hline Workers & Dysfunctional & $0.25 * *(0.32)$ & $0.24 * *(0.31)$ & $0.26 * *(0.36)$ & $0.24 * *(0.32)$ & $0.31 * *$ \\
\hline ALL & Functional & 0.05 & $0.17 * *$ & -0.05 & $-0.17 * *$ & -0.02 \\
\hline Students & Functional & 0.00 & $0.19 * *$ & 0.04 & -0.10 & 0.02 \\
\hline Adolescents & Functional & $0.25 * *$ & $0.19 * *$ & 0.09 & -0.10 & $0.13 *$ \\
\hline Workers & Functional & -0.01 & $0.16 * *$ & $-0.20 * *$ & $-0.23 * *$ & -0.11 \\
\hline \multicolumn{7}{|c|}{ Controlling for DI } \\
\hline ALL & Functional & 0.00 & $0.116^{* *}$ & $-0.10 * *$ & $-0.21 * *$ & $-0.09 *$ \\
\hline Students & Functional & -0.03 & 0.12 & 0.01 & -0.12 & 0.01 \\
\hline Adolescents & Functional & $0.21 * *$ & $0.16^{*}$ & 0.03 & $-0.14 *$ & 0.08 \\
\hline Workers & Functional & -0.06 & $0.13^{*}$ & $-0.25 * *$ & $-0.28 * *$ & $-0.17 * *$ \\
\hline
\end{tabular}

${ }^{* *} p<0.01{ }^{*} p<0.05$ 
Table 3

Product moment correlations between Anger and the AQ scales across samples and partial correlations controlling for DI. The dissattenuated correlation coefficients are between brackets

\begin{tabular}{|c|c|c|c|c|}
\hline Sample & Variable & $\mathrm{PA}$ & VA & $\mathrm{HO}$ \\
\hline All & Anger & $0.51 * *(0.69)$ & $0.46 * *(0.64)$ & $0.51 * *(0.72)$ \\
\hline Students & Anger & $0.44 * *(0.59)$ & $0.50 * *(0.69)$ & $0.33 * *(0.46)$ \\
\hline Adolescents & Anger & $0.55 * *(0.74)$ & $0.38 * *(0.53)$ & $0.47 * *(0.66)$ \\
\hline Workers & Anger & $0.42 * *(0.57)$ & $0.52 * *(0.72)$ & $0.58 * *(0.86)$ \\
\hline \multicolumn{5}{|c|}{ Controlling for Dysfunctional Impulsivity } \\
\hline All & Anger & $0.44 * *$ & $0.41 * *$ & $0.47 * *$ \\
\hline Students & Anger & $0.39 * *$ & $0.46^{* *}$ & $0.34 * *$ \\
\hline Adolescents & Anger & $0.48 * *$ & $0.32 * *$ & $0.43 * *$ \\
\hline Workers & Anger & $0.37 * *$ & $0.49 * *$ & $0.55^{* *}$ \\
\hline
\end{tabular}

${ }^{* *} p<0.01 * p<0.05$

more controlled and anger feelings are more related to verbal expressions than to physical aggressions. On the other hand, anger seems highly related to hostility, especially among the workers and adolescents. It seems that high levels of anger may be related to resentment which is one of the components of many items of this scale.

Table 3 also shows partial correlation coefficients between $\mathrm{AN}$ and the other scales of AQ controlling for DI. As can be seen, partial correlation coefficients are slightly lower than zero order correlation coefficients. This result seems to indicate that DI has effects on the relationship between AN and aggression but it is not the only factor to affect the relationships proposed between anger and aggression.

\section{Discussion}

The results obtained by relating impulsivity and aggression seem to indicate that previous results in this domain using DII and AQ in samples of university students (see for instance, Archer et al., 1995; Vigil-Colet \& Codorniu-Raga, 2004) are generalizable to other samples such as adolescents or workers. Before discussing these results, we have to take into account that when we talk about the relationship between impulsivity and aggression we are referring specifically to DI. This is an important issue because, as Smillie and Jackson (2006) pointed out, impulsivity is a common name for a multitude of dimensions and it is necessary to specify to which dimension of impulsivity we are referring. In our case DI is viewed as a dimension that reflects the classical definition of impulsivity, which implies that impulsive individuals are characterized by acting with less forethought and adopting non-reflexive response strategies that may be inappropriate to the situation.

The results presented above show that DI is related to all AQ scales, in particular to AN, PA and VA scales (in this order). These results indicate that impulsivity is specially related to instrumental and emotional aspects of aggression, which is consistent with the notion of impulsive aggression proposed by Barratt (1991, 1994), and which implies that DI is related more to aggressive actions at a specific moment than to the cognitive aspects measured by the hostility scale. Nevertheless, when we analyse the relationships between anger and aggression controlling for DI, the relationship between anger and aggression decreases slightly but is still significant. This seems to indicate that, as Barratt proposed some years later (Barratt \& Slaughter, 1998; Barratt, Stanford, Kent, \& Felthous, 1997), impulsivity is not a sufficient condition for impulsive aggression and many other variables need to be taken into account.

Worthy of particular mention is FI's negative relationship with AN and especially with HO. The negative relationship between FI and HO was previously reported by Vigil-Colet and Codorniu-Raga (2004) in a small sample of university students and our results seem to confirm this relationship. Although further research is needed to clarify this issue we think that one possible explanation for this relationship is the capacity of FI individuals to take speedy decisions when the consequences will be positive. This ability may be related to other variables such as self-esteem, problem-solving abilities, and so forth, which may reduce the levels of resentment (a component of $\mathrm{HO}$ ) and anger.

Sex is also shown to have significant effects on PA. Previous research has shown that sex has effects only on PA and VA (Archer et al., 1995; Bernstein \& Gesn, 1997; Ramirez, Andreu, \& Fuhihara, 2001; Williams, Boyd, Cascardi, \& Poythress, 1996) although the effects on VA are much slighter than on PA. Our results, then, seem to confirm that gender effects on AQ are mainly based on the PA scale, being men more physically aggressive than women, and that these effects are stable across samples.

We found that the correlation coefficients between impulsivity and aggression measures for men and women were not significantly different. This result is different from 
the one reported by Archer and Webb (2006) who found that impulsivity is more related to physical PA and HO in men than in women. Nevertheless, Archer and Webb obtained these results from an on-line sample of university students with many more women than men. They also used a different measure of impulsivity, the BIS-11 questionnaire. Further research is needed to determine whether the relationships between impulsivity and aggression depend on sex and whether these differences can depend on the sample or the instrument used.

Another interesting result is the higher scores of the adolescent group on the AQ scales and DI, and the relationships between these variables in this group. It is well known that the changes from adolescence to adulthood lead to more controlled and less reckless behaviour and a decrease in anger levels (Roberts, Caspi, \& Moffitt, 2001; Spear, 2000). This characteristics of adolescent individuals are reflected in their higher scores in the PA, AN, and $\mathrm{HO}$ scales of the AQ and in their higher scores in DI. Furthermore, anger in adolescents shows a different pattern of relationships with the other scales of the AQ because anger has a greater relationship with physical aggression than with verbal aggression. It seems that young individuals are more susceptible to becoming physically aggressive and that, as they get older, they move on to other more controlled kinds of aggression. In the adult groups, however, anger seems to show a tendency to be more expressed in verbal aggression than in physical aggression. Finally, anger is more related to hostility in the samples of adolescents and workers than in the university students.

The results of this study show that the relationship between impulsivity and aggression is stable across samples and focused on instrumental (specially with PA) and emotional aspects of aggressive behaviour. Nevertheless, impulsivity seems to be one predictor (among others) of this kind of behaviour. This result is consistent with Barrat theory of impulsive aggression, which proposes that lack of inhibition is necessary but not sufficient for impulsive aggression. Impulsivity is, therefore, a variable that mediates the expression of aggression. Further research is needed to determine the variables other than impulsivity that are involved in the origins of impulsive aggression. Variables such as poor verbal processing abilities or social-problem skills may play an important role (Barratt et al., 1997; Barratt \& Slaughter, 1998; McMurran et al., 2002).

\section{References}

Andreu, J. M., Peña, M. E., \& Graña, J. L. (2002). Adaptación psicométrica de la versión española del Cuestionario de Agresión. Psicothema, 14(2), 476-482.

Archer, J. (2004). Sex differences in real-word settings: A metaanalytic review. Review of General Psychology, 8, 291-332.

Archer, J., Kilkpatrick, G., \& Bramwell, R. (1995). Comparison of two aggression inventories. Aggressive Behavior, 21, 371-380.
Archer, J., \& Webb, I. A. (2006) The relation between scores on the Buss-Perry Aggression Questionnaire and aggressive acts, impulsiveness, competitiveness, dominance, and sexual jealousy. Aggressive Behavior, 32, 464-473.

Ávila, C., \& Parcet M. A. (1997). Impulsivity and anxiety differences in cognitive inhibition. Personality and Individual Differences, 23(6), 1055-1064.

Barratt, E. S. (1991). Measuring and predicting aggression within the context of a personality theory. Journal of Neuropsychiatry, 3, 535-539.

Barratt, E. S. (1994). Impulsiveness and Aggression. In J.Monahan \& H.J.Steadman (Eds.), Violence and mental disorders: Developments in risk assessment (pp. 61-79). Chicago: The University of Chicago Press.

Barratt, E. S., \& Slaughter, L. (1998). Defining, measuring, and predicting impulsive aggression: A heuristic model. Behavioral Sciences and the Law, 16, 285-302.

Barratt, E. S., Stanford, M. S., Dowdy, L., Liebman, M. J., \& Kent, T. A. (1999). Impulsive and premeditated aggression: A factor analysis of self-reported acts. Psychiatry Research, 86,163173.

Barratt, E. S., Stanford, M. S., Kent, T. A., \& Felthous, A. (1997). Neuropsychological and cognitive psychophysiological substrates of impulsive aggression. Biological Psychiatry, 41, 1045-1061.

Bernstein, I. H., and Gesn, P. R. (1997). On the dimensionality of the Buss-Perry Aggression Questionnaire. Behavior Research and Therapy, 35, 563-568.

Buss, A. H., \& Perry, M. P. (1992). The Aggression Questionnaire. Journal of Personality and Social Psychology, 63(3), 452-459.

Chico, E., Tous, J., M., Lorenzo-Seva U., \& Vigil-Colet A. (2003). Spanish adaptation of Dickman's Impulsivity Inventory: Its relationship to Eysenck's Personality Questionnaire. Personality and Individual Differences, 35, 1883-1892.

Condon, L., Morales-Vives, F., Ferrando, P. J, \& Vigil-Colet, A. (2006). Sex differences in the full and reduced versions of the Aggression Questionnaire: A question of differential item functioning? European Journal of Psychological Assessment, 22, 92-97.

Dickman, S. J. (1990). Functional and dysfunctional impulsivity: Personality and cognitive correlates. Journal of Personality and Social Psychology, 58(1), 95-102.

Eysenck, H. J. (1993). The nature of impulsivity. In W. G. McCown, J. L. Johnson, \& M. B. Shure (Eds.), The impulsive client: Theory, research and treatment (pp. 57-70). Washington, D.C.: American Psychological Association.

Eysenck, S. B. G. (1997). Psychoticism as a dimension of personality. In H.Nyborg (Ed.), The scientific study of human nature (pp. 109-121). Oxford, England: Elsevier Science.

Eysenck, S. B. G., Pearson, P. R., Easting, G., \& Allsopp, J.F. (1985). Age norms for impulsiveness, venturesomeness, and empathy in adults. Personality and Individual Differences, 6 , 613-619.

Felthous, A.R. (1998) Introduction to impulsive aggression. Behavioral Sciences and the Law, 13,281-283. 
Ferrando, P. J., Condon, L., \& Chico, E. (2004). The convergent validity of acquiescence: An empirical study relating balanced scales and separate acquiescence scales. Personality and Individual Differences, 37, 1331-1340.

Fink, A. D., \& McCown, W. G. (1993). Impulsivity in children and adolescents: Measurement, causes and treatment. In W. McCown, J. L. Johnson, \& M. B. Shure (Eds.), The impulsive client: Theory, research and treatment (pp. 279-308). Washington, DC: American Psychological Association.

Gerbing, D. W., Ahadi, S. A., \& Patton, J. H. (1987) Toward a conceptualisation of impulsivity: Components across the behavioural and self-report domains. Multivariate Behavioral Research, 22, 357-379.

Helfritz, L. E., \& Stanford, M. S. (2006). Personality and psychopathology in an impulsive-aggressive college sample. Aggressive Behavior, 32, 28-37.

Horna, N. R., Dolan, M., Elliott, R., Deakin, J. F., \& Woodruff, P. W. (2003). Response inhibition and impulsivity: An fMRI study. Neuropsychologia, 41, 1959-1966

Logan, G. D., Schachar, R. J., \& Tannock, R. (1997). Impulsivity and inhibitory control. Psychological Science, 8, 60-64.

Marsh, D. M., Dougherty, D. D., Mathias, C. W., Moeller, F. G., \& Hicks, L. R. (2002). Comparisons of women with high and low trait impulsivity using behavioral models of responsedisinhibition and reward-choice. Personality and Individual Differences, 33, 1291-1310.

McMurran, M., Blair, M., \& Egan, V. (2002). An investigation of the correlations between aggression, impulsiveness, social problem-solving, and alcohol use. Aggressive Behavior 28, 439-445.

Miller, J., Flory, K., Lynam, D., \& Leukefeld, C. (2003). A test of the four-factor model of impulsivity related traits. Personality and Individual Differences, 34, 1403-1418.

Miller, E., Joseph, S., \& Tudway, J. (2004). Assessing the component structure of four self-report measures of impulsivity. Personality and Individual Differences, 37, 349-358.

Morales-Vives, F. (2007). El efecto de la impulsividad sobre la agresividad y sus consecuencias en el rendimiento de los adolescentes. Unpublished doctoral dissertation, Universitat Rovira i Virgili, Tarragona, Spain.

Morales-Vives, F., Codorniu-Raga, M. J., \& Vigil-Colet, A. (2005). Psychometric properties of the reduced versions of Buss and Perry's Aggression Questionnaire. Psicothema. 17, 96-100.

O'Connor, D. B., Archer, J., Hair, M., \& Wu, F. W. C. (2002). Exogenous testosterone, aggression and mood in eugonadal and hypogonadal men. Physiology and Behavior. 75, 557-566.
Patton, J. H., Stanford, M. S., \& Barratt, E. S. (1995). Factor structure of the Barratt Impulsiveness Scale. Journal of Clinical Psychology, 51, 768-774.

Ramirez, J. M., \& Andreu, J. M. (2006). Aggression, and some related psychological constructs (anger, hostility, and impulsivity): Some comments from a research project. Neuroscience and Biobehavioral Reviews, 30, 276-291.

Ramírez, J., Andreu, J. M., \& Fujihara, T. (2001). Cultural and sex differences in aggression: A comparison between Japanese and Spanish students using two different inventories. Aggressive Behavior, 27, 313-322.

Roberts, B. W., Caspi, A., \& Moffitt, T. E. (2001). The kids are allright: Growth and stability in personality development from adolescence to adulthood. Journal of Personality and Social Psychology. 81, 670-683.

Shadish, W. R., Cook, T. D., \& Campbell, D. T. (2002). Experimental and quasi-experimental designs for generalized causal inference. Boston: Houghton Mifflin.

Smillie, L. D., and Jackson, C. J. (2006). Functional impulsivity and reinforcement sensitivity theory. Journal of Personality, $74,47-83$.

Spear, L. P. (2000). The adolescent brain and age-related behavioral manifestations. Neuroscience and Biobehavioral Reviews, 24 ,417-463

Vigil-Colet, A. (2007). Impulsivity and decision-making in the balloon analogue risk-taking task. Personality and Individual Differences, 43, 37-45.

Vigil-Colet, A., \& Codorniu-Raga, M.J. (2004). Aggression and inhibition deficits: The role of functional and dysfunctional impulsivity. Personality and Individual Differences. 37, 14311440 .

Vigil-Colet, A., \& Morales-Vives, F. (2005). How impulsivity is related to intelligence and academic achievement. The Spanish Journal of Psychology, 8, 199-204.

Whiteside, S. P., \& Lynam, D. R. (2001). The five-factor model and impulsivity: Using a structural model of personality to understand impulsivity. Personality and Individual Differences, 30, 669-689.

Williams, T. Y., Boyd, J. C., Cascardi, M. A., \& Poythress, N. (1996). Factor structure and convergent validity of the Aggression Questionnaire in an offender population. Psychological Assessment, 4, 398-403.

Received September 18, 2007 Revision received January 23, 2008 Acepted May 7, 2008 